\title{
In vivo demonstration of microvascular thrombosis in severe COVID-19
}

\author{
Douglas Alexandre do Espírito Santo ${ }^{1}$ Anna Cristina Bertoldi Lemos ${ }^{1} \cdot$ Carlos Henrique Miranda $^{1}$ (i)
}

Accepted: 4 August 2020 / Published online: 13 August 2020

(c) Springer Science+Business Media, LLC, part of Springer Nature 2020

\begin{abstract}
Several autopsy studies showed microthrombi in pulmonary circulation of severe COVID-19 patients. The major limitation of these investigations is that the autopsy provided static information. Some of these alterations could be secondary to the disseminated intravascular coagulation (DIC) observed as the final standard route to the multisystem organ failure exhibited in critically ill patients. We report preliminary results of an in vivo evaluation of sublingual microcirculation in thirteen patients with severe COVID-19 requiring mechanical ventilation. We observed multiple filling defects moving within the microvessels indicative of thrombi in most of the cases 11/13 (85\%). This is the first imaging documentation of microvascular thrombosis in living severe COVID-19 patients since the beginning of the hospitalization. The clinical relevance of microvascular thrombosis in this disease requires further research.
\end{abstract}

Keywords COVID-19 $\cdot$ Microvascular thrombosis $\cdot$ Sublingual microcirculation $\cdot$ Coagulopathy

\section{Highlights}

- Microthrombi in pulmonary circulation is a common finding in autopsies of severe COVID-19 patients.

- In vivo evaluation of sublingual microcirculation of severe COVID-19 patients showed multiple filling defects moving within the microvessels indicative of thrombi in most of the cases.

- This is the first imaging documentation of microvascular thrombosis in living severe COVID-19 patients.

- The clinical relevance of microvascular thrombosis in COVID-19 requires further research.

Electronic supplementary material The online version of this article (https://doi.org/10.1007/s11239-020-02245-x) contains supplementary material, which is available to authorized users.

Carlos Henrique Miranda chmiranda@fmrp.usp.br

1 Division of Emergency Medicine, Department of Internal Medicine, Ribeirão Preto School of Medicine, São Paulo University, Rua Bernardino de Campos, 1000, Ribeirão Preto, SP 14020-670, Brazil

\section{Introduction}

The main clinical presentation of patients with severe coronavirus disease 2019 (COVID-19) is an acute respiratory failure with significant hypoxemia, which ultimately requires mechanical ventilation [1]. In addition to the gas exchange involved, recently published investigations described a high incidence of thrombotic events in these patients [2].

Several autopsy studies demonstrated microthrombi in pulmonary circulation [3-6]. The major limitation of these investigations is that the autopsy provided static information. Some of these alterations could be secondary to the disseminated intravascular coagulation (DIC) observed as the standard route to the multisystem organ failure exhibited in critically ill patients.

To support the importance of microvascular thrombosis in severe COVID-19 pathophysiology, we report preliminary results of an in vivo evaluation of sublingual microcirculation allowing the dynamic visualization of these microvessels.

\section{Methods}

We included adult patients with SARS-CoV-2 virus infection confirmed through reverse transcriptase polymerase chain reaction (RT-PCR) of nasopharyngeal swabs and 
severe clinical presentation with respiratory failure requiring mechanical ventilation. The sublingual microcirculation visualization was performed with the patient in dorsal decubitus and with the headboard raised to 45 degrees. We used the Capiscope HVCS handheld video capillaroscopy system (KK Technology, Honiton, England, UK), and imaging was analyzed using the Glycocheck system (Microvascular health solution, American Fork, UT, USA). Protected with disposable tips and without being pressed, the camera was placed under the tongue in at least five different regions inside the mouth after the patient's admission into the intensive care unit.

The ethical board of our institution approved this investigation. Patients' relatives gave their written informed consent to participate in this research.

\section{Results}

We analyzed the imaging of the sublingual microcirculation of thirteen patients on the first day after hospital admission. The demographics, clinical, and laboratory characteristics of these patients are presented in Table 1 . All the patients were on mechanical ventilation, and they did not have any evidence of circulatory shock. Six patients (46\%) were using a low norepinephrine dose to support sedation and neuromuscular blocking agents, both of them with normal lactate. None of these patients met the criteria for DIC. Despite elevated D-dimer levels, prothrombin time and activated partial thromboplastin time (aPTT) were normal, fibrinogen levels were increased in all patients and mild thrombocytopenia was observed in only two of them.

We observed some evidence of microvascular thrombosis in 11 patients (85\%). For comparison, an example of the normal sublingual microcirculation in a healthy individual is presented in Fig. 1a and b. The arrows in Fig. 1c-e illustrate filling defects moving within the microvessels indicative of thrombi, which were found in 11 patients $(85 \%)$. Four patients (31\%) exhibited complete stagnated capillaries. We observed microvessels with the interrupted flow and semioval imaging in its distal extremity suggesting acute thromboembolic occlusion (asterisk in Fig. 1f) in 5 patients (38\%). An abrupt thromboembolic obstruction of a microvessel was registered during the evaluation in 3 patients (videos in supplementary material).

\section{Discussion}

Thrombus in small vessels of the pulmonary circulation is a common finding in autopsies of COVID-19 patients. Dolhnikoff et al. [3] observed a variable number of small fibrinous thrombi in small pulmonary arterioles in areas of both damaged and more preserved lung parenchyma in 8 out of 10 cases in the minimally invasive autopsy. Small fibrinous thrombi were rarely found in the glomeruli and superficial dermal vessels. Ackermann et al. [4] examined seven lungs obtained during the autopsy and found widespread pulmonary vessels' thrombosis. Fox et al. [5] observed the presence of thrombosis and microangiopathy in the lungs' small vessels and capillaries in autopsies of ten African American decedents. Carsana et al. [6] analyzed lung tissue samples of 38 patients, besides the diffuse alveolar damage, they observed fibrin thrombi in small arterial vessels in $87 \%$ of cases, around half of which had more involvement than $25 \%$ of the lung tissue.

Our investigation demonstrated thrombi in microcirculation since the beginning of the hospitalization and none of these patients had criteria for DIC. This finding reinforces that microvascular thrombosis is a hallmark of the COVID-19.

Another conclusion emphasized by our investigation is that microvascular thrombosis occurs systemically and it could affect different organs. Probably those organs with a high capillary density, such as the lungs, are the most compromised. In the lung, pulmonary microvascular thrombosis could lead to a dead-space effect (ventilated areas, but not perfused), contributing to the critical hypoxemia observed in these cases. However, microvascular thrombosis could compromise other areas such as the kidney, liver, and brain, contributing to multiple organ dysfunction, such as recent descriptions [7]. This mechanism could explain the findings of Tang et al. [8], who in a retrospective study achieved a low 28-day mortality in severe COVID-19 patients with the use of anticoagulant therapy for seven days or more, especially the ones with high sepsis-induced coagulopathy score $(\geq 4)$ or high D-dimer levels $(\geq 3.0 \mathrm{mg} / \mathrm{l})$.

This virus causes an intense inflammatory response with massive pro-inflammatory cytokines release, such as interleukin (IL) $-1, \mathrm{IL}-6, \mathrm{IL}-8$, and interferon $-\gamma$, associated with endothelial vascular damage causing a hypercoagulable state, which leads to microvascular thrombosis $[9,10]$. Some authors suggest using MicroCLOTS (microvascular COVID19 lung vessels obstructive thromboinflammatory syndrome) as an adequate name for this severe pulmonary presentation [11]. As all these alterations are diffuse, we expected to find systemic microvascular thrombosis, as we described in the sublingual territory. Since the pulmonary capillaries assessment is challenging in living patients, we generalize that the same should happen in pulmonary microcirculation.

Quintana-Castenedo et al. [12] reported retinal vasculitis with perivascular infiltrate and retinal exudates in ocular fundus examination of a child with COVID-19, they did not describe vascular obstruction in the retinal vessels. Besides the clinical presentation in children is milder, we considered that sublingual evaluation provides a more 
Table 1 Characteristics of the COVID-19 patients in whom sublingual microcirculation was assessed

\begin{tabular}{|c|c|}
\hline Parameters & $\mathrm{n}=13$ \\
\hline \multicolumn{2}{|l|}{ Demographic } \\
\hline Age (years), mean \pm sd & $58 \pm 11$ \\
\hline Male, n $(\%)$ & $10(77)$ \\
\hline \multicolumn{2}{|l|}{ Clinical presentation } \\
\hline Fever, n $(\%)$ & $11(85)$ \\
\hline Cough, n (\%) & $12(92)$ \\
\hline Dyspnea, n (\%) & $13(100)$ \\
\hline Myalgia, n (\%) & $7(54)$ \\
\hline Duration of symptoms (days), median (IQR) & $6(4-9)$ \\
\hline \multicolumn{2}{|l|}{ Risk factors } \\
\hline Diabetes mellitus, n (\%) & $4(31)$ \\
\hline Hypertension, n (\%) & $4(31)$ \\
\hline Cardiovascular disease, $\mathrm{n}(\%)$ & $1(08)$ \\
\hline Immunocompromise, $\mathrm{n}(\%)$ & $1(08)$ \\
\hline BMI $\left(\mathrm{Kg} / \mathrm{m}^{2}\right)$, mean $\pm \mathrm{sd}$ & $34 \pm 9$ \\
\hline \multicolumn{2}{|l|}{ Physical Examination } \\
\hline Systolic blood pressure $(\mathrm{mmHg})$, mean $\pm \mathrm{sd}$ & $120 \pm 23$ \\
\hline Diastolic blood pressure $(\mathrm{mmHg})$, mean $\pm \mathrm{sd}$ & $74 \pm 11$ \\
\hline Heart rate (beats per minute), mean \pm sd & $79 \pm 19$ \\
\hline Mechanical ventilation, n (\%) & $13(100)$ \\
\hline Tidal volume $(\mathrm{ml})$, mean $\pm \mathrm{sd}$ & $374 \pm 66$ \\
\hline PEEP $(\mathrm{cm}$ of water $)$, mean $\pm \mathrm{sd}$ & $12 \pm 3$ \\
\hline Plateau pressure ( $\mathrm{cm}$ of water), mean $\pm \mathrm{sd}$ & $24 \pm 4$ \\
\hline Static compliance $(\mathrm{ml} / \mathrm{cm}$ of water), mean $\pm \mathrm{sd}$ & $33 \pm 8$ \\
\hline Respiratory rate (cycles/min), mean \pm sd & $24 \pm 4$ \\
\hline $\mathrm{FiO} 2(\%)$, range (min-max) & $0.55-1.00$ \\
\hline \multicolumn{2}{|l|}{ Drugs } \\
\hline Norepinephrine, n (\%) & $6(46)$ \\
\hline Midazolam, n (\%) & $13(100)$ \\
\hline Fentanyl, n (\%) & $13(100)$ \\
\hline Neuromuscular blocking agent, $\mathrm{n}(\%)$ & $13(100)$ \\
\hline Hydroxychloroquine, n (\%) & $3(23)$ \\
\hline Macrolide antibiotic, n (\%) & $13(100)$ \\
\hline Corticosteroids, n (\%) & $9(69)$ \\
\hline Antiplatelet agents, n (\%) & $0(00)$ \\
\hline Therapeutic LMWH, n (\%) & $6(46)$ \\
\hline Prophylactic LMWH, n (\%) & $7(54)$ \\
\hline \multicolumn{2}{|l|}{ Laboratory test } \\
\hline Hemoglobin $(\mathrm{g} / \mathrm{dl})$, mean $\pm \mathrm{sd}$ & $13 \pm 2$ \\
\hline White-cell count (per microliter), mean \pm sd & $8232 \pm 4149$ \\
\hline Platelets count (per microliter), mean \pm sd & $234,231 \pm 55,853$ \\
\hline Creatinine clearance $(\mathrm{ml} / \mathrm{min})$, mean $\pm \mathrm{sd}$ & $69 \pm 18$ \\
\hline Creatinine $(\mathrm{mg} / \mathrm{dl})$, mean $\pm \mathrm{sd}$ & $1.2 \pm 0.3$ \\
\hline D-Dimer ( $\mu \mathrm{g} / \mathrm{L})$, median (IQR) & $1830(1120-2320)$ \\
\hline Fibrinogen (mg/dl), median (IQR) & $767(672-843)$ \\
\hline aPTT (Ratio), median (IQR) & $1.16(1.06-1.20)$ \\
\hline Prothrombin time (INR), median (IQR) & $1.06(1.03-1.18)$ \\
\hline C-reactive protein $(\mathrm{mg} / \mathrm{L})$, mean $\pm \mathrm{sd}$ & $18 \pm 8$ \\
\hline Lactate $(\mathrm{mg} / \mathrm{dl})$, mean $\pm \mathrm{sd}$ & $1.7 \pm 0.4$ \\
\hline $\mathrm{PaO} 2 / \mathrm{FiO} 2$ ratio, mean $\pm \mathrm{sd}$ & $128 \pm 32$ \\
\hline Chest radiography with bilateral opacities, n (\%) & $13(100)$ \\
\hline
\end{tabular}


Table 1 (continued)

\begin{tabular}{ll}
\hline Parameters & $\mathrm{n}=13$ \\
\hline Scores, median (IQR) & \\
SOFA & $10(8-11)$ \\
SAPS 3 & $56(49-68)$ \\
DIC score (ISTH) & $2(2-3)$ \\
SIC score & $2(2-2)$ \\
ARDS classification & \\
Severe, $\mathrm{n}(\%)$ & $2(15)$ \\
Moderate, $\mathrm{n}(\%)$ & $11(85)$ \\
\hline
\end{tabular}

$s d$ standard deviation, $I Q R$ interquartile range, $B M I$ body mass index, $P E E P$ positive end-expiratory pressure, $\mathrm{PaO} 2$ partial pressure of arterial oxygen, $\mathrm{FiO} 2$ fraction of inspired oxygen, $L M W H$ low-molecularweight heparin, aPTT activated partial thromboplastin time, INR international normalized ratio, SOFA sequential organ failure assessment score, SAPS 3 simplified acute physiology score 3, DIC International Society of Thrombosis and Hemostasis criteria for disseminated intravascular coagulation, SIC sepsisinduced coagulopathy score, $A R D S$ acute respiratory distress syndrome
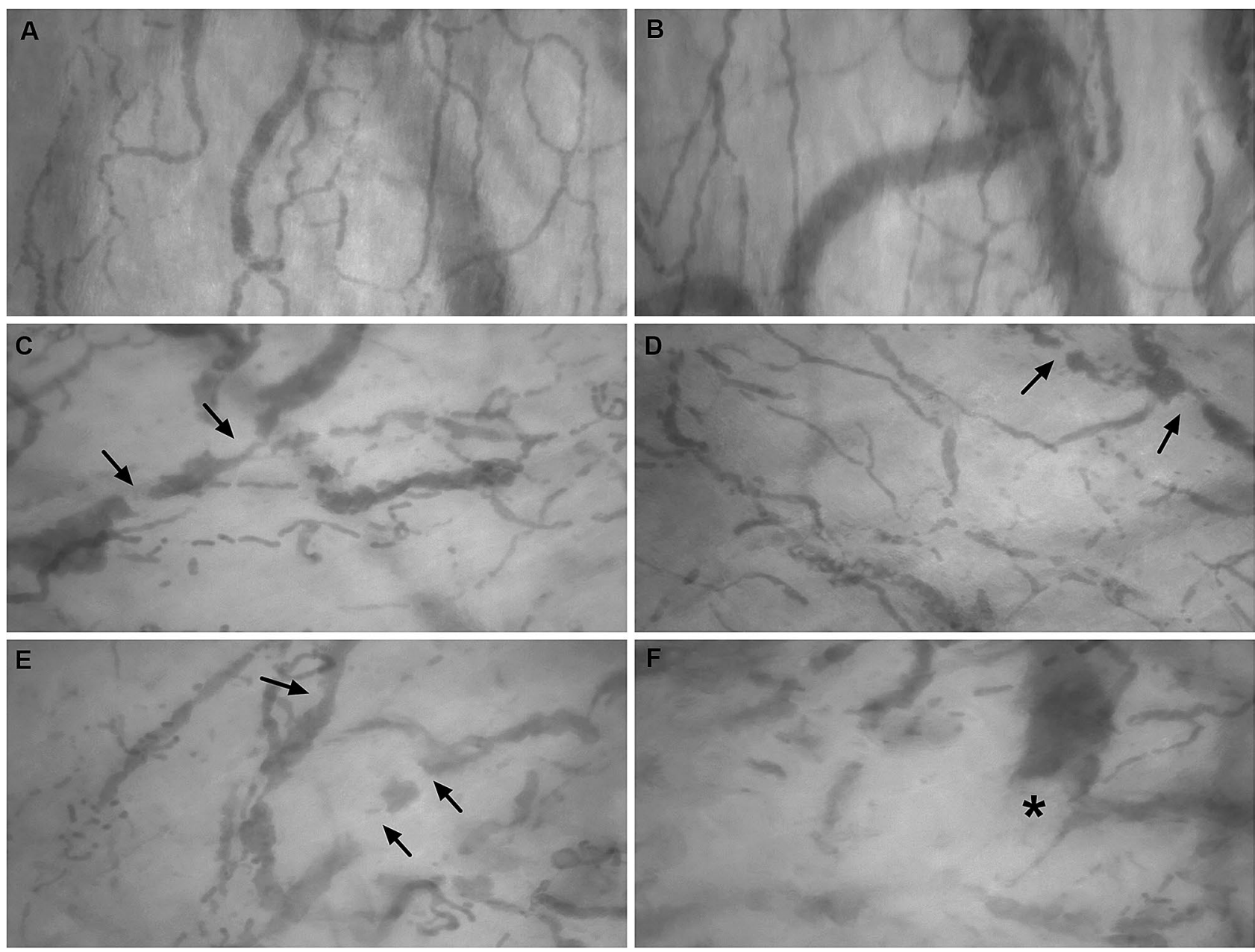

Fig. 1 Normal sublingual microcirculation in a healthy individual $(\mathbf{a}-\mathbf{b})$. Presence of several filling defects (arrows) moving inside the microvessels indicative of thrombi $(\mathbf{c}-\mathbf{e})$ in severe COVID-19 patients. Microvessel with interrupted flow showing semi-oval imaging (asterisk) in its distal extremity compatible with acute thromboembolic occlusion (f) in COVID-19 patient 
detailed assessment of microcirculation than funduscopic examination.

This is a descriptive study of a small series of COVID19 patients. There was no control group in this investigation. Despite the microcirculatory alterations are frequently observed in critically ill patients [13], especially in patients with sepsis, similar findings of multiple filling defects moving within the microvessels are not described in these patients. We considered that the endotracheal tube did not influence in sublingual microcirculation evaluation, because previous studies in mechanically ventilated patients did not observe this interference. In summary, this is the first imaging documentation of microvascular thrombosis in living severe COVID-19 patients since the beginning of the hospitalization. The clinical relevance of microvascular thrombosis in COVID-19 requires further research.

Author contribution DAES-acquisition of data, analysis and interpretation of data, draft the article, final approval of the last version. ACBL-acquisition of data, analysis and interpretation of data, draft the article, final approval of the last version. CHM-conception and design of the study, acquisition of data, analysis and interpretation of data, draft the article, final approval of the last version.

Funding This research was supported by grants of the Fundação de Amparo a Pesquisa do Estado de São Paulo (FAPESP), process number: 2019/06187-1.

Data availability The data used and/or analyzed during the current study are available from author corresponding author on reasonable request.

\section{Compliance with ethical standards}

Conflict of interest All authors declare no conflicts of interest.

Ethical approval The study was approved by the Research Ethics Committee of our institution and followed the Declaration of Helsinki.

Informed consent The subjects or their relatives gave their written informed consent to participate of this research.

\section{References}

1. Berlin DA, Gulick RM, Martinez FJ (2020) Severe Covid-19. N Engl J Med. https://doi.org/10.1056/NEJMcp2009575

2. Klok FA, Kruip M, van der Meer NJM, Arbous MS, Gommers D, Kant KM, Kaptein FHJ, van Paassen J, Stals MAM, Huisman MV,
Endeman H (2020) Incidence of thrombotic complications in critically ill ICU patients with COVID-19. Thromb Res 191:145-147. https://doi.org/10.1016/j.thromres.2020.04.013

3. Dolhnikoff M, Duarte-Neto AN, de Almeida Monteiro RA, Ferraz da Silva LF, Pierre de Oliveira E, Nascimento Saldiva PH, Mauad T, Marcia Negri E (2020) Pathological evidence of pulmonary thrombotic phenomena in severe COVID-19. J Thromb Haemost. https://doi.org/10.1111/jth.14844

4. Ackermann M, Verleden SE, Kuehnel M, Haverich A, Welte T, Laenger F, Vanstapel A, Werlein C, Stark H, Tzankov A, Li WW, Li VW, Mentzer SJ, Jonigk D (2020) Pulmonary vascular endothelialitis, thrombosis, and angiogenesis in Covid-19. N Engl J Med. https://doi.org/10.1056/NEJMoa2015432

5. Fox SE, Akmatbekov A, Harbert JL, Li G, Quincy Brown J, Vander Heide RS (2020) Pulmonary and cardiac pathology in African American patients with COVID-19: an autopsy series from New Orleans. Lancet Respir Med. https://doi.org/10.1016/S2213 -2600(20)30243-5

6. Carsana L, Sonzogni A, Nasr A, Rossi RS, Pellegrinelli A, Zerbi P, Rech R, Colombo R, Antinori S, Corbellino M, Galli M, Catena E, Tosoni A, Gianatti A, Nebuloni M (2020) Pulmonary postmortem findings in a series of COVID-19 cases from northern Italy: a two-centre descriptive study. Lancet Infect Dis. https:// doi.org/10.1016/S1473-3099(20)30434-5

7. Sise ME, Baggett MV, Shepard JO, Stevens JS, Rhee EP (2020) Case 17-2020: a 68-year-old man with Covid-19 and acute kidney injury. N Engl J Med. https://doi.org/10.1056/NEJMcpc2002418

8. Tang N, Bai H, Chen X, Gong J, Li D, Sun Z (2020) Anticoagulant treatment is associated with decreased mortality in severe coronavirus disease 2019 patients with coagulopathy. J Thromb Haemost 18(5):1094-1099. https://doi.org/10.1111/jth.14817

9. Iba T, Levy JH, Levi M, Thachil J (2020) Coagulopathy in COVID-19. J Thromb Haemost. https://doi.org/10.1111/jth.14975

10. Tan CW, Low JGH, Wong WH, Chua YY, Goh SL, Ng HJ (2020) Critically ill COVID-19 infected patients exhibit increased clot waveform analysis parameters consistent with hypercoagulability. Am J Hematol. https://doi.org/10.1002/ajh.25822

11. Ciceri F, Beretta L, Scandroglio AM, et al. (2020) Microvascular COVID-19 lung vessels obstructive thromboinflammatory syndrome (MicroCLOTS): An atypical acute respiratory distress syndrome working hypothesis. Crit Care Resusc. 22(2):95-97

12. Quintana-Castanedo L, Feito-Rodríguez M, Fernández-Alcalde C, Granados-Fernández M, Montero-Vega D, Mayor-Ibarguren A, Lucas Laguna R (2020) Concurrent chilblains and retinal vasculitis in a child with COVID-19. J Eur Acad Dermatol Venereol. https://doi.org/10.1111/jdv.16801

13. de Backer D, Ospina-Tascon G, Salgado D, Favory R, Creteur J, Vincent JL (2010) Monitoring the microcirculation in the critically ill patient: current methods and future approaches. Intensive Care Med 36:1813-1825. https://doi.org/10.1007/s0013 4-010-2005-3

Publisher's Note Springer Nature remains neutral with regard to jurisdictional claims in published maps and institutional affiliations. 